\title{
Vascular and Subcortical Dementia
}

\section{Michelle Blose*}

Department of Cardiovascular Surgery, Nagano Red Cross Hospital, 22-1-5 Wakasato, Nagano 380-8582, Japan

\section{Introduction}

Vascular dementia (VAD), a disabling loss of cognitive function caused by cerebrovascular disease [1], is the second most common cause of dementia in the USA [2]. In fact, around $15-20 \%$ of all dementia cases are caused by cerebrovascular disease after Alzheimer's disease $(\mathrm{AD})$. VAD has a prevalence of $1.5 \%$ in the general population, occurring almost exclusively in elderly adults. Understanding the causes and risks associated with the disease will help physicians provide treatment and support for patients as well as caretakers.

\section{Risk Factors}

Some people are more at risk of developing vascular dementia than others. Age is one of the most important, as not only does VAD increase with advancing age, but so does incident of clinical stroke $[1,3,4]$. Other demographic factors include race/ethnic group (mainly Asian), sex (male), low education, and living in rural area. Atherogenic factors (hypertension, cigarette smoking, heart disease, diabetes, hyperlipaemia, and menopause with oestrogen replacement therapy) and non-atherogenic factors (genetic, alteration in haemostasis, high alcohol consumption, use of aspirin, psychological stress, occupational exposure such as pesticides, herbicides, etc.) increase risks as well [5]. Hypertension is one of the most experimentally-proven risk factors, as several studies suggest that "elevated blood pressure measured in midlife increases the risk of dementia or accelerates age-related cognitive decline" [5]. The APOE $\varepsilon 4$ genotype is a modest risk factor for cardiovascular disease [6] and $\mathrm{AD}$ [7], but not incident stroke [8]. Furthermore, silent infarcts, which cause an area of the brain to die due to lack of blood flow, are known as "silent" because patients have no clinical history of stroke; these infarcts cause greater cognitive decline [9] and increase the risk of subsequent dementia [1].

Because stroke is one of the most important causes of VAD, they share many similar risk factors. Indeed, "cardiovascular risk factors are associated with clinically diagnosed AD [10-12] and VAD [13,14]. According to Micieli, after an acute stroke, 4 to $9 \%$ developed dementia, reaching $15 \%$ after one year and $23 \%$ following patients with a lacunar infarction for a period of four years [15]. Others say dementia occurs in $25 \%$ of stroke victims, while even other sources estimate as many as $30 \%$ get dementia within the six months following a stroke [16]. The disparity in statistics may be explained by different measurements, as the incident rate using NINDS_AIREN is $4 \%$ while that of the DSM-IV is $29 \%$ [1].

Subcortical dementia has its own set of risk factors. Risk factors for white matter lesions, a precursor to dementia, include increased plasma homocysteine [17], decreased serum tryptophan [18], low serum antioxidant levels [19], hyperinsulinemia [20], and hyperfibrinogenemia [19]. Genetics could also be a factor, such as Cerebral Autosomal Dominant and Subcortical Ischemic Leukoencephalopathy (CADASIL), a defect on the Notch 3 gene of chromosome 19 [21], that presents young and has features of premature frontal-subcortical dysfunction. African Americans seem to be more susceptible to small vessel stroke [11], but this may only be due to hypertension $[22,23]$.

\section{Etiology}

Cerebrovascular disease manifests itself in many different forms. Either it is a result of a stroke, in which case it can be either singleinfarct (stroke in a critical brain region), multi-infarct (repeated stroke), or else is operating much more covertly as small vessel disease (chronic microvascular ischemia [inadequate blood supply] without a discrete infarct). Both types of cerebrovascular disease are results of the accumulation of atherosclerosis, emboli, and/or aneurism.

Atherosclerosis is a "hardening of the arteries" and occurs when cholesterol, calcium, and other substances build up in the inner lining of the arteries, forming plaque. These substances usually are deposited in a tear in the artery wall, and the ultimately severely narrowed artery can then become more easily blocked by a blood clot.

Emboli are floating blood clots or plaque in blood vessels. They tend to lodge in bifurcations (branchings, curvatures) in the arterial system. If there are enough emboli, thrombosis (a solidified blood within a vessel) will occur, which will either block blood flow, causing brain tissue death in the efferent areas, or will break off.

An aneurism is a weak patch on an artery wall that can balloon outward, burst and deprive the brain cells of oxygen. There are different forms of aneurism: fusiform or true aneurisms form a symmetrical bulge of the artery; saccular or "false" aneurisms are bulbous and form only on one side of the artery wall; pseudoaneurisms are small blisters that form asymmetrically on the wall. A ruptured aneurism would occur upon the bursting of the inflated patch of arterial wall, creating hemorrhaging in that area of the brain. Aneurisms occur in 1 to $6 \%$ of the population.

\section{VAD Subtypes by Pathology: Cortical (Stroke-Related)}

Vascular dementia can by caused by one of the most dramatic forms of cerebrovascular disease: stroke. Single Infarct Dementia is the dementia that occurs with an acute infarct, usually the result of a clinical stroke, and can impact any area in the brain. It has an abrupt onset and a stable course, possibly resulting in significant impairment in cognition. This may be observed in cases of anterior cerebral artery infarct, parietal lobe infarcts, thalamic infarction, and singular gyrus infarction. Micieli claim that infarcts in the thalamus, left internal capsule genu, or caudate nucleus cause VAD, while Knopman would add the hippocampus, dominant perisylvian region, or nondominant

*Corresponding author: Michelle Blose, Department of Cardiovascular Surgery, Nagano Red Cross Hospital, 221-5 Wakasato, Nagano 380-8582, Japan, Tel: 724428-0179; E-mail: Michelle.Blose@va.gov

Received November 27, 2017; Accepted December 11, 2017; Published December 17, 2017

Citation: Blose M (2017) Vascular and Subcortical Dementia. J Vasc Med Surg 5 351. doi: 10.4172/2329-6925.1000351

Copyright: (c) 2017 Blose M. This is an open-access article distributed under the terms of the Creative Commons Attribution License, which permits unrestricted use, distribution, and reproduction in any medium, provided the original author and source are credited. 
posterior perisylvian region [5]. Cognitive improvements may take place weeks to months after a stroke, but deficits may be permanent [1]

The second type of VAD is Multi-Infarct Dementia, so called because it results from many infarcts throughout the brain caused by mini-strokes. When this is the case, cognitive decline is less specific, as these infarcts are in many different locations. Multi-Infarct Dementia is also referred to as Stepwise VAD because there are long periods of cognitive stability through which the level of cognitive performance remains the same, followed by a sudden decline after another ministroke. This type of VAD is important because typically physicians look for a history of clinical stroke to diagnose VAD, yet this dementia can occur without this. In fact, only half of the subjects with radiologic evidence of critical ischemic lesions had a history of clinical stroke or focal motor deficits [24]. Sometimes the mini-strokes last less than one day; at this point they are called Transient Ischemic Attacks.

\section{VAD Subtypes by Pathology: Subcortical (Not Stroke- Related)}

Unlike the former two subtypes, Microvascular Ischemic Disease (aka small vessel disease) is unrelated to the incident of stroke in the patient and is the most common subtype of VAD [25]. Small Vessel Disease (SVD) affects the small vessels of the brain, which can be found deep under the cortex, where the former two subtypes occur. SVD results in arterial wall changes, expansion of the Virchow-Robin spaces, perivascular parenchymal rarefaction and gliosis. SVD often causes white matter hyperintensities (WMH), which are characterized by demyelination, enlarged perivascular spaces, and occasionally infarctions. Although often caused by cerebrovascular disease, etiologies also include toxic, metabolic, infectious, and degenerative conditions [26,27]. The incident rate of WMH increases with age [28], is associated with hypertension [28,29], diabetes, cigarette smoking, or elevated homocysteine level. WMH is associated with greater risk of stroke, cognitive impairment [30] and cognitive decline [31] as well as an increased risk of developing dementia [32] and cerebrovascular disease. Small vessel disease constitutes a "disruption of the frontalsubcortical or medial temporal limbic circuits" [33,34], which is the cause of the aforementioned disabilities, as well as a marked loss of balance [35]. Especially when resulting in leukoaraiosis, SVD may produce subcortical vascular dementia, characterized by slowed cognition, memory impairment, visual spatial deficits, EF deficits and mood/affect disturbance. Initial cognitive deficits can present subtly and progress slowly over time, growing from hardly detectable impairments to Binswanger disease or a lacunar state, two different manifestations of subcortical VAD.

Although both Binswanger disease and lacunar state have similar symptoms, they are etiologically different. Binswanger disease, also known as subcortical leukoencephalopathy, is a diffuse white matter disease. Vascular changes observed are fibrohyalinosis of the small arteries and fibrinoid necrosis of the larger vessels inside the brain. Urinary complaints are common in Binswanger's disease and may precede cognitive impairment by up to five years [36]. Detrusor hyperreflexia is likely to be the underlying urodynamic abnormality [37], caused by lesions in medial frontal lobes and basal ganglia [38]. In addition to Binswanger's disease, "many patients with extensive white matter changes also have lesions in the basal ganglia and thalamus that often correspond to 'silent' lacunar infarction [39]." A lacunar infarct will result when small vessel occlusions produce small cavitary lesions, called lacunae, within the brain parenchyma secondary to occlusion of small penetrating arterial branches. These lacunae are found more typically in the internal capsule, deep gray nuclei, and white matter. Lacunar state is a condition in which numerous lacunae, which indicate widespread, severe SVD, are present; symptoms occur depending on where the lacunae are located.

\section{Neuropsychological Patterns of VAD}

As there are many different subtypes of vascular dementia, "there is no reason to suspect that only one neuropsychological profile could capture these differences in underlying pathologies [39]." Furthermore, the diversity of infarct locations and sizes makes for a clinically heterogeneous disorder [1]. A wide variety of cognitive deficits from stroke should be possible because any brain region could be involved in a zone of infarction. Prominent amnesic disturbances, aphasia, visuospatial deficits, and executive deficits are all possible in patients with pure cerebrovascular disease [1]. There is a greater likelihood of attentional and executive deficits and a lower likelihood of anterograde amnesia [40]. Just as there is no clear neuropsychological profile for VAD, a cognitive profile is not sufficient to establish whether cerebrovascular disease has attributed to these dysfunctions [1].

Therefore, common neuropsychological patterns of VAD include cognitive slowing, difficulties in assessing shifting sets, and problems with abstraction. Speed, dexterity, executive functioning, and motor aspects of speech are all impaired. Patients usually experience apathy. Free recall and perseverant behavior (compared) is increased, whereas verbal fluency and intrusions are decreased. Memory problems may or may not be a prominent symptom, depending on whether brain regions important in memory are affected.

In subcortical VAD, recognition and cued memory are often wellpreserved [40], whereas mostly executive functioning is impaired. Latelife affective disorders may also be related to microvascular changes in elderly patients $[41,42]$. Lesions in both the subcortical white matter [43] and deep nuclei [44] are associated with late-life depression. In the "Vascular Depression Hypothesis," [45] subcortical vascular changes in depressed elderly patients are associated with poor response to antidepressants [46] and electroconvulsive therapy [47] and a greater risk for dementia and death $[48,49]$.

\section{Diagnosing VAD}

There is poor agreement among the different diagnostic schemes used to identify VAD [50,51]. Alzheimer's disease Diagnosis and Treatment Center (ADDTC) has broader classifications [2]. DSMIV is the most inclusive, while the National Institute of Neurological Disorders and Stroke-Association Internationale pour la Recherche et l'Enseignement en Neurosciences (NINDS-AIREN) is the most specific. ADDCT classifications used with the Hachinski Ischemic Score (HIS) can distinguish Alzheimer's from VAD [5]. Neurologic signs, such as hemiparesis, hemianopia, or hemisensory loss suggest cerebral localization, but a reflex asymmetry or an isolated extensor toe sign doesn't suggest cerebrovascular origin because of the lower specificity of the isolated neurological signs [1]. No focal neurological signs are necessary for a diagnosis of VAD because of the heterogenous nature of the disease.

Not only do diagnostic tools fail to accurately identify even the same cohorts [2], but imaging techniques also fall short in being able to predict VAD. No consistent pattern of infarction exists in those who developed dementia and those who did not [1]. However, there are reliable ways to diagnose cerebrovascular disease, the precursor to VAD. The detection of infarcts that are larger than lacunae can be used as a reliable indicator of cerebrovascular disease. History of stroke and 
neurologic signs also has clear specificity in affirming the presence of cerebrovascular disease [1].

Blessed et al. [49] suggested infarct volume as a determinate for a diagnosis of VAD, but Knopman points out that the research group did not consider lesion location [1]. There is no way to relate location and size to severity of cognitive impairment, as there is no threshold of infarction agreed upon that persistently results in dementia. Although there is no way to directly relate infarcts to dementia, the greater the size and number of infarcts, the greater likelihood that they will affect cognition. MRI is good at detecting subcortical microangiopathic changes because of the high resolution and distinction between gray and white matter [39]. There is a significant discrepancy between the diagnosis made with and without MRI, so diagnoses of VAD should be done using parallel diagnostic criteria for $\mathrm{VAD}$ and for $\mathrm{AD}$, assisted with neuroimaging studies [2].

Because dementia may occur after a stroke, searching for signs of dementia directly after a clinical stroke may prove very beneficial to the long-term health of the patient. In fact, "From a clinician's perspective, the possibility of post-stroke dementia should be factored into planning for medical care during the first year after a stroke [1]," especially if risk factors were present before. Cognitive impairment in stroke survivors is under-recognized because of the overwhelming nature of other stroke-related deficits such as hemiparesis, hemianopia, or aphasia [1]. It is important to evaluate stroke patients during the acute phase after a stroke to detect later alterations in cognitive function by using MMSE, [52] which evaluates "orientation, recall and various attention, calculation and language skills" [53]. However, the results of this device may be skewed if the patient has low English literacy, visual or hearing impairment, or other communication difficulties. Patients also sometimes feel as if the questions are not worth answering or will refuse to participate to hide their deficits [54-57]. Other helpful diagnostic tools include Street's Completion Test, Trail Making, Raven Matrix, IADL and ADL Scales, Neuropsychiatric Inventory, HRSD, and the Cornell Scale for Depression in Dementia [5].

\section{Differential Diagnosis: VAD vs. AD}

Vascular Dementia and Alzheimer's disease, although organically separate, present with similar symptoms in a similar population as well as often occurring concurrently. They have similar biological substrates: hippocampal atrophy is common in $\mathrm{AD}$, but subcortical ischemic vascular disease can also affect hippocampal volume [32]. Cerebral atherosclerosis and other vascular factors, which are direct causes for $\mathrm{VAD}$, are associated with a higher risk of $\mathrm{AD}$ [57]. The diseases even have similar survival rates [58], perhaps because clinically defined $\mathrm{VAD}$ and $\mathrm{AD}$ both are highly likely to have pathologic contributions from both cerebrovascular disease and $\mathrm{AD}$ [1].

As the differences between the two diseases are difficult to detect, diagnostic criteria will produce variant diagnoses. Criteria from the ADDTC identified participants in the border zone between AD and VAD or those with no history of clinical strokes but with severe MRIidentified vascular disease [2]. Because the ADDTC doesn't specify how to classify dementia, it can be used with the criteria set forth by the National Institute of Neurological and Communicative Disorders and Stroke and Alzheimer's disease and Related Disorders Association (NINCDS-ADRDA) to explore the relationship between VAD and AD [2]. However, it is very common for more common diagnostic tools to misclassify $\mathrm{AD}$ for $\mathrm{VAD}$ and vice versa, or to discount certain aspects of one on the other. As a result of the failings of diagnostic tests, "AD can never be ruled out [1]."
Pure VAD, if it can occur, would be more likely to occur in younger patients, but it is much more likely to have pure AD than VAD. Knopman would suggest that we look at both diseases as two ends of a continuum [1]. If the patient has VAD, he or she will need fewer $\mathrm{AD}$ pathologic features to produce the same degree of dementia [5963]. A greater degree of cerebrovascular disease implies less $A D$ and vice versa, for a particular level of cognitive impairment [1]. According to one study, half of the patients with clinically diagnosed VAD had concomitant $\mathrm{AD}$ at autopsy $[64,65]$.

There are a few differences that help to distinguish both types of dementia. $\mathrm{AD}$ is characterized by a subtle onset with progressively worsening symptoms over time, whereas VAD may occur suddenly in stroke-related cases, then progressing in a stepwise manner, although usually onset is also gradual. The incident rates of both types of dementia increase with age [66], but VAD typically occurs sooner, in ages 65 to 70. As a general rule, though, "AD should almost always be considered present" [67].

\section{Dementia, Major Depression, and Depressive Pseudodementia}

Cognitive, affective, and behavioral changes may occur after a stroke $[67,68]$. If these changes are overlooked, they can worsen the rehabilitative process [69]. They can be due to psychological factors, such as loss of function and mobility and changes in interpersonal relationships [70], but could have a neurobiological origin. Differentiating between the etiologies of depressive symptoms is important for treatment, and this can be done by recognizing differences in symptomatology. Often, "low motivational" symptoms were organically caused [71].

In an attempt to determine post-stroke depression from dementia, Naarding et al. subdivided depressive disorder into different dimensions, establishing a "mood" dimension, including "depressed mood, anger, negative and suicidal thoughts, ruminations, and social withdrawal," a psychomotor dimension, consisting of "psychomotor retardation, observed depression and loss of energy," and a vegetative dimension consistent of loss of appetite and subsequent weight [67]. All three factors are associated with DSM diagnosis of major depressive disorder, but the psychomotor dimension was also firmly associated with dementia. Because the psychomotor factor is highly correlated to diagnoses of both depression and dementia, difficulties in clinical decision making are expected. In addition, non-depressed patients with dementia also commonly displayed vegetative symptoms.

Differentiating between dementia and depressive pseudodementia can be done by observing variation between symptoms and test performance. For dementia, cognitive changes occur first. Patients are cooperative but their performance on the MMSE is often poor or fails to accurately express their real level of cognitive impairment. Aphasia may be present, and patients can enjoy things. In depressive pseudodementia, mood changes occur first, mood being consistently dysphoric. When asked to take the MMSE, patients are uncooperative or will not try. Aphasia is absent, patients cannot enjoy life, and delirium may be present as well.

\section{Delirium vs. Dementia}

There are many ways to distinguish delirium from dementia. Delirium has an abrupt, precise onset with an identifiable date. It is an acute illness, generally lasting days to weeks but rarely more than one month, as it is usually reversible. Delirium can be caused by 
nearly any disease that affects the brain, including toxic-metabolic disturbances and traumatic, vascular, infectious, neoplastic, epileptic, nutritional or psychiatric pathophysiologic entities, with incident rates increasing with age [72]. Symptomatically, disorientation occurs early, and there is a lot of variability in clinical presentation from moment to moment, hour to hour, throughout the day. There are prominent physiological changes, as well as clouded, altered and changing levels of consciousness. The attention span is markedly reduced, the sleepwake cycle is disturbed from hour to hour, and there are marked psychomotor changes, both of the hyperactive or hypoactive variety.

Dementia, on the other hand, often has a gradual onset that cannot be precisely dated. It is a chronic illness, characteristically progressing over the years, and is generally irreversible. Disorientation occurs later in the illness, often after months or years. Patients are much more stable from day to day, unless delirium develops. When delirium does occur in dementia patients, it is usually caused by urinary tract infections, pneumonia, unwitnessed trauma with related pain or medication errors. Less common causes include stroke, seizures, meningitis, or subdural hematoma [72]. There are less prominent physiological changes. Consciousness is not clouded until terminal stages, attention span is not characteristically reduced, and the sleep-wake cycle, although disturbed, consists of a day-night reversal instead of an hour to hour variation. Psychomotor changes occur characteristically late, unless depression develops.

\section{Treatment Options/Recommendations}

Vascular dementia has no known cure, so treatment usually focuses on managing behavior, protecting patient safety, maintaining dignity and supporting caregivers. Often, Complementary and Alternative Medicine (CAM), which is a patient-led approach to healthcare that operates outside the realm of medical practice, can dramatically improve patient behavior by alleviating anxiety, agitation, combativeness, and increasing the patient's ability to communicate feelings and needs; examples of these simple practices include aromatherapy and painting [73]. CAM and other palliative care methods not only improve the lives of patients, but of their caregivers as well. Most caregivers report feeling overwhelmed, receiving little to no outside help and being unable to find time to join community support groups [74]. Doctors should make caregivers aware of social services such as senior centers, senior day care, Meals on Wheels, and transportation services, as well as advising caregivers on where to find counseling and behavioral management advice [53].

Although most caregivers prefer medications that improve behavioral and daily living skills over those that improve cognitive skills, doctors are still searching for pharmaceuticals that treat VAD. Since it is related to three different conditions, $\mathrm{AD}$, hypertension, and $\mathrm{WMH}$, treatments for these conditions have been applied to the treatment of VAD. AD treatments have included the use of cholinesterase inhibitors, which prevent the breakdown of acetylcholine, a neurotransmitter important in memory and cognition [75]; galantamine [76] or donepezil [77,78] gave modest benefits, as did Memantine, [79,80] but none have been given regulatory approval specifically for VAD. These drugs' success could be attributed to the nonspecific nature of the drugs or concomitant AD findings [1]. Hypertension medication that has been applied include perindopril and indapamide, which reduced VAD incidence from $7.1 \%$ to $6.3 \%[81,82]$. Antihypertensive therapy, such as candesartan, may reduce cognitive decline and stroke incidence. Control of hypertension has also been shown to be a meaningful effect: a Syst-Eur study [83] showed that dementia can be prevented with the calcium-entry blocker nitrendipine and ACE inhibitors enalapril, but SHEP [84] showed that "thiazidic diuretic (clortalidone) and a beta-blocker (atenolol) [do not] have the same effects in the prevention of cognitive impairment." In the treatment of subcortical VD specifically, "calcium antagonist nimodipine has shown some benefit" [5]. However, most pharmaceutical treatment is centered on reducing depression, relieving restlessness, or controlling aggressive or agitated behavior [85].

Because dementia is incurable, prevention is the most powerful tool doctors have to fight it. New approaches to screening for loss of executive control function in primary care are needed [25], as currently executive control function is not emphasized during routine medical examinations. If possible, it would be best to identify patients with Mild Neurocognitive Disorder first, as this may progress to dementia later on. These patients, once identified, will require a unique approach to care planning due to symptomatic apathy [85]. In addition to early detection, there are well-established therapies to prevent cardiovascular disease starting in midlife that might have a great impact on future disability [39]. As research continues to progress, our hopes of learning how to effectively treat vascular dementia come closer to being realized.

\section{References}

1. Knopman DS (2006) Dementia and Cerebrovascular Disease. Mayo Clin Proc 81: $223-230$.

2. Lopez OL, Kuller LH, Becker JT, Jagust WJ, De Kosky ST, et al. (2005) Classification of vascular dementia in the Cardiovascular Health Study Cognition Study. Neurology 64: 1539-1547.

3. Knopman DS, Rocca WA, Cha RH, Edland SD, Kokmen E (2002) Incidence of vascular dementia in Rochester, Minn, 1985-1989. Arch Neurol 59: 1605-1610.

4. Lobo A, Launer LJ, Fratiglioni L, Andersen K, Di Carlo A, et al. (2000) Prevalence of dementia and major subtypes in Europe: a collaborative study of population-based cohorts. Neurologic Diseases in the Elderly Research Group. Neurology 54: 4-9.

5. Micieli G (2006) Vascular Dementia. Neurol Sci 27: 37-39.

6. Eichner JE, Dunn ST, Perveen G, Thompson DM, Stewart KE, et al. (2002) Apolipoprotein Epolymorphism and cardiovascular disease: a HuGE review. Am J Epidemiol 155: 487-495.

7. Farrer LA, Cupples LA, Haines JL, Hyman B, Kukull WA, et al. (1997) Effects of age, sex, and ethnicity on the association between apolipoprotein $E$ genotype and Alzheimer disease. A meta-analysis. APOE and Alzheimer Disease MetaAnalysis Consortium. JAMA 278: 1349-1356.

8. Slooter AJ, Cruts M, Hofman A, Koudstaal PJ, van der Kuip D, et al. (2004) The impact of APOE on myocardial infarction, stroke, and dementia: the Rotterdam Study. Neurology 62: 1196-1198.

9. Longstreth WT, Dulberg C, Manolio TA, Lewis MR, Beauchamp NJ, et al (2002) Incidence, manifestations, and predictors of brain infarcts defined by serial cranial magnetic resonance imaging in the elderly: the Cardiovascular Health Study. Stroke 33: 2376-2382.

10. Breteler MM, Bots ML, Ott A, Hofman A (1998) Risk factors for vascular disease and dementia. Haemostasis 28: 167-173.

11. Kuller LH, Lopez OL, Newman A, Beauchamp NJ, Burke G, et al. (2003) Risk factors for dementia in the Cardiovascular Health Cognition Study. Neuroepidemiology 22: 13-22.

12. Luchsinger JA, Reitz C, Honig LS, Tang MX, Shea S, et al. (2005) Aggregation of vascular risk factors and risk of incident Alzheimer disease. Neurology 65 545-551.

13. Ross GW, Petrovitch H, White LR, Masaki KH, Li CY, et al. (1999) Characterization of risk factors for vascular dementia: the Honolulu-Asia Aging Study. Neurology 53: 337-343.

14. Hebert R, Lindsay J, Verreault R, Rockwood K, Hill G, et al. (2000) Vascula dementia: incidence and risk factors in the Canadian study of health and aging. Stroke 31: 1487-1493. 
15. Tatemichi TK, Desmond DW, Paik M, Figueroa M, Gropen TI, et al. (1993) Clinical determinants of dementia related to stroke. Ann Neurol 33: 568-575.

16. Tatemichi TK, Desmond DW, Stern Y, Paik M, Sano M, et al. (1994) Cognitive impairment after stroke: frequency, patterns, and relationship to functional abilities. J Neurol Neurosurg Psychiatry 57: 202-207.

17. Fassbender K, Mielke O, Bertsch T, Nafe B, Froschen S, et al. (1999) Homocysteine in cerebral macroangiography and microangiopathy. Lancet 353: $1586-1587$

18. Yao H, Yuzuriha T, Koga H, Fukuda K, Endo K, et al. (1999) Decreased plasma tryptophan associated with deep white matter lesions in elderly subjects. J Neurol Neurosurg Psychiatry 66: 100-103.

19. Schmidt H, Fazekas F, Kostner GM, Schmidt R (2000) Genetic aspects of microangiopathy-related cerebral damage. J Neural Transm Suppl 19: 312-319.

20. Zunker P, Schick A, Buschmann HC, Georgiadis D, Nabavi DG, et al. (1996) Hyperinsulinism and cerebral microangiopathy. Stroke 27: 219-223.

21. Viitanen $M$, Kalimo $H(2000)$ CADASIL: hereditary arteriopathy leading to multiple brain infarcts, and dementia. Ann N Y Acad Sci 903: 273-284.

22. Gorelick PB (1998) Cerebrovascular disease in African Americans. Stroke 29 : 2656-2664.

23. Liao D, Cooper L, Cai J, Toole J, Bryan N, et al. (1997) The prevalence and severity of white matter lesions, their relationship with age, ethnicity, gender, and cardiovascular disease risk factors: The ARIC Study. Neuroepidemiology 16: 149-162.

24. Roman GC, Royall DR (1999) Executive control function: a rational basis for the diagnosis of vascular dementia. Alzheimer Dis Assoc Disord 13: 69-80.

25. Filley CM (1998) The behavioral neurology of cerebral white matter. Neurology 50: $1535-1540$

26. Van Gijn J (1998) Leukoaraiosis and vascular dementia. Neurology 51: 3-8.

27. Longstreth WT, Manolio TA, Arnold A, Burke GL, Bryan N, et al. (1996) Clinical correlates of white matter findings on cranial magnetic resonance imaging of 3301 elderly people: the Cardiovascular Health Study. Stroke 27: 1274-1282.

28. Breteler MM, van Swieten JC, Bots ML, Grobbee DE, Claus JJ, et al. (1994) Cerebral white matter lesions, vascular risk factors, and cognitive function in a population-based study: the Rotterdam Study. Neurology 44: 1246-1252.

29. De Groot JC, de Leeuw FE, Oudkerk M, Van Gijn J, Hofman A, et al. (2000) Cerebral white matter lesions and cognitive function: the Rotterdam Scan Study. Ann Neurol 47: 145-151.

30. De Groot JC, De Leeuw FE, Oudkerk M, Van Gijn J, Hofman A, et al. (2002) Periventricular cerebral white matter lesions predict rate of cognitive decline. Ann Neurol 52: 335-341.

31. Prins ND, Van Dijk EJ, Den Heijer T, Vermeer SE, Koudstaal PJ, et al. (2004) Cerebral white matter lesions and the risk of dementia. Arch Neurol 61: 15311534.

32. Cummings JL (1993) Frontal-subcortical circuits and human behavior. Arch Neurol 50: 873-880.

33. Kramer JH, Reed BR, Mungas D, Weiner MW, Chui HC (2002) Executive dysfunction in subcortical ischemic vascular disease. J Neurol Neurosurg Psychiatry 72: 217-220.

34. Tell GS, Lefkowitz DS, Diehr P, Elster AD (1998) Relationship between balance and abnormalities in cerebral magnetic resonance imaging in older adults. Arch Neurol 55: 73-79.

35. Kotsoris H, Barclay LL, Kheyfets S, Hulyalkar A, Dougherty J (1987) Urinary and gait disturbances as markers for early mulit-infarct dementia. Stroke 18 : $138-141$

36. Resnick NM (1995) Urinary incontinence. Lancet 346: 94-99.

37. De Groot JC, De Leeuw FE, Oudkerk M, Hofman A, Jolles J, et al. (2000) Cerebral white matter lesions and depressive symptoms in elderly adults. Arch Gen Psychiatry 57: 1071-1076.

38. Pugh KG, Lipsitz LA (2002) The microvascular frontal-subcortical syndrome of aging. Neurobiology of Aging 23: 421-431.

39. Looi JC, Sachdev PS (1999) Differentiation of vascular dementia from AD on neuropsychological tests. Neurology 53: 670-678.
40. Fujikawa T, Yamawaki S, Touhouda Y (1993) Incidence of silent cerebra infarction in patients with major depression. Stroke 24: 1631-1634.

41. Robinson RG, Chemerinski E, Jorge R (1999) Pathophysiology of secondary depressions in the elderly. J Geriatr Psychiatry Neurol 12: 128-136.

42. Steffens DC, Helms MJ, Krishnan KR, Burke GL (1999) Cerebrovascula disease and depression symptoms in the cardiovascular health study. Stroke 30: 2159-2166.

43. Alexopoulos GS, Meyers BS, Young RC, Campbell S, Silbersweig D, et al. (1997) 'Vascular depression' hypothesis. Arch Gen Psychiatry 54: 915-922.

44. Simpson S, Balwin RC, Jackson A, Burns AS (1998) Is subcortical disease associated with a poor response to antidepressants? Neurological neuropsychological and neuroradiological findings in late-life depression. Psychol Med 28: 1015-1026.

45. Steffens DC, Conway CR, Dombeck CB, Wagner HR, Tupler LA, et al. (2001) Severity of subcortical gray matter hyperintensity predicts ECT response in geriatric depression. J Ect 17: 45-49.

46. O'Brien J, Ames D, Chiu E, Schweitzer I, Desmond P, et al. (1998) Severe deep white matter lesions and outcome in elderly patients with major depressive disorder; follow up study. BMJ 317: 982-984

47. Van Exel E, Westendorp RG, Stek ML, Van Tilburg W, Beekman AT, et al. (2001) Patients with late-onset depression have poor cognitive function at old age. J Am Geriatr Soc 49: 231-233.

48. Chui H, Mack W, Jackson JE, Mungas D, Reed BR, et al. (2000) Clinical criteria for the diagnosis of vascular dementia: a multicenter study of comparability and interrater reliability. Arch Neurol 57: 191-196.

49. Blessed G, Tomlinson BE, Roth M (1968) The association between quantitative measures of dementia and of senile change in the cerebral grey matter of elderly subjects. Br J Psychiatry 114: 797-811

50. Folstein MF, Folstein SE, McHugh PR (1975) A practical method for grading the cognitive state of patients for the clinician. J Psychiatr Res 12: 189-198.

51. Shagam JY (2009) The Many Faces of Dementia. Radiologic Technology 81 153-168.

52. Death J, Douglas A, Kenny RA (1993) Comparison of clock drawing in Mini Mental State Examination as a screening test in elderly acute hospital admissions. Postgrad Med J 69: 696-700.

53. Simpson JR (2014) DSM-5 and Neurocognitive Disorders. JAAPL 42: 159-164

54. Grohol JM (2014) Symptoms of Major Neurocognitive Disorder. Psych Central.

55. Honig LS, Kukull W, Mayeux R (2005) Atherosclerosis and AD: analysis of data from the US National Alzheimer's Coordinating Center. Neurology 64: 494-500.

56. Wolfson C, Wolfson DB, Asgharian M, M'Lan CE, Østbye T, et al. (2001) A reevaluation of the duration of survival after the onset of dementia. $\mathrm{N}$ Engl $J$ Med 344: 1111-1116.

57. Heyman A, Fillenbaum GG, Welsh-Bohmer KA, Gearing M, Mirra SS, et al. (1998) Cerebral infarcts in patients with autopsy-proven Alzheimer's disease: CERAD, part XVIII. Consortium to Establish a Registry for Alzheimer's Disease. Neurology 51: 159-162.

58. Snowdon DA, Greiner LH, Mortimer JA, Riley KP, Greiner PA, et al. (1997) Brain infarction and the clinical expression of Alzheimer disease: The Nun Study. JAMA 277: 813-817.

59. Schneider JA, Wilson RS, Bienias JL, Evans DA, Bennett DA (2004) Cerebral infarctions and the likelihood of dementia from Alzheimer disease pathology. Neurology 62: 1148-1155.

60. Petrovitch H, Ross GW, Steinhorn SC, Abbott RD, Markesbery W, et al. (2005) $A D$ lesions and infarcts in demented and non-demented Japanese-American men. Ann Neurol 57: 98-103.

61. Riekse RG, Leverenz JB, McCormick W, Bowen JD, Teri L, et al. (2004) Effect of vascular lesions on cognition in Alzheimer's disease: a community-based study. J Am Geriatr Soc 52: 1442-1448.

62. Esiri MM, Wilcock GK, Morris JH (1997) Neuropathological assessment of the lesions of significance in vascular dementia. J Neurol Neurosurg Psy chiatry 63: 749-753.

63. Tomlinson BE, Blessed G, Roth M (1970) Observations on the brain of demented old people. J Neurol Sci 11: 205-242. 
64. Braak H, Braak E (1997) Frequency of stages of Alzheimer-related lesions in different age categories. Neurobiol Aging 18: 351-357.

65. Sharpe M, Hawton K, House A, Molyneux A, Sandercock P, et al. (1990) Mood disorders in long- term survivors of stroke: associations with brain lesion location and volume. Psychol Med 20: 815-828.

66. Kotila M, Numminen H, Waltimo O, Kaste M (1999) Post-stroke depression and functional recovery in a population based stroke register. The Finnstroke study. Eur J Neurol 6: 309-312.

67. Naarding P, De Koning I, Van Kooten F, Dippel DWJ, Janzing JGE, et al. (2003) Depression in vascular dementia. Int J Geriatr Psychiatry 18: 325-330.

68. Forsell Y, Jorm AF, Fratiglioni L (1993) Application of DSM- III-R criteria for major depressive episode to elderly subjects with and without dementia. Am J Psychiatry 150: 1199-1202.

69. Gossman H, Bergmann C, Parker S (2006) Dementia: A brief review. The Mount Sinai Journal of Medicine 7: 985-992.

70. Complementary and alternative medicine for dementia

71. The Alzheimer's caregiver perspective.

72. Evaluating prescription drugs used to treat: Alzheimer's disease.

73. Erkinjuntti T, Kurz A, Gauthier S, Bullock R, Lilienfeld S, et al. (2002) Efficacy of galantamine in probable vascular dementia and Alzheimer's disease combined with cerebrovascular disease: a randomised trial. Lancet 359: 1283-1290.

74. Black S, Roman GC, Geldmacher DS, Salloway S, Hecker J, et al. (2003) Efficacy and tolerability of donepezil in vascular dementia: positive results of a 24-week, multicenter, international, random- ized, placebo-controlled clinical trial. Stroke 34: 2323-2330.

75. Wilkinson D, Doody R, Helme R, Taubman K, Mintzer J, et al. (2003) Donepezi 308 Study Group. Donepezil in vascular dementia: a randomized, placebocontrolled study. Neurology 61: 479-486.
76. Wilcock G, Mobius HJ, Stoffler A, MMM 500 Group (2002) A double-blind, placebo-controlled multicentre study of memantine in mild to moderate vascular dementia (MMM 500). Int Clin Psychopharmacol 17: 297-305

77. Orgogozo JM, Rigaud AS, Stoffler A, Mobius HJ, et al. (2002) Efficacy and safety of memantine in patients with mild to moderate vascular dementia: a randomized, placebo-controlled trial (MMM 300). Stroke 33: 1834-1839.

78. Tzourio C, Anderson C, Chapman N, Woodward M, Neal B, et al. (2003) Effects of blood pressure lowering with perindopril and indapamide therapy on dementia and cognitive decline in patients with cerebrovascular disease. Arch Intern Med 163: 1069-1075.

79. Skoog I, Lithell $H$, Hansson L, Elmfeldt D, Hofman A, et al. (2005) Effect of baseline cognitive function and antihypertensive treatment on cognitive and cardiovascular outcomes: Study on Cognition and Prognosis in the Elderly (SCOPE). Am J Hypertens 18: 1052-1059.

80. Forette F, Seux ML, Staessen JA, Thijs L, Birkenhäger WH, et al. (1998) Prevention of dementia in randomised double-blind placebo-controlled Systolic Hypertension in Europe (Syst-Eur) trial. Lancet 352: 1347-1351.

81. SHEP Cooperative Research Group (1991) Prevention of stroke by antihypertensive drug treatment in older persons with isolated systolic hypertension. Final results of the Systolic Hypertension in the Elderly Program (SHEP). JAMA 265: 3255-3264.

82. http://www.neurology.health-cares.net/vascular-dementia-treatments.php

83. Cummings JL (1994) Vascular subcortical dementias: clinical aspects. Dementia 5: 177-180.

84. Fogel BS (1994) The significance of frontal system disorders for medica practice and health policy. J Neuropsychiatry Clin Neurosci 6: 343-347.

85. Grafman J, Litvan I (1999) Importance of deficits in executive functions. Lancet 345: 1921-1923. 